Article

\title{
Using Remote Sensing to Analyse Net Land-Use Change from Conflicting Sustainability Policies: The Case of Amsterdam
}

\author{
Mendel Giezen *D, Stella Balikci and Rowan Arundel \\ Department of Human Geography, Planning and International Development Studies, Amsterdam Institute of \\ Social Science Research, University of Amsterdam, 1018 WZ Amsterdam, The Netherlands; \\ stellabalikci@gmail.com (S.B.); r.i.m.arundel@uva.nl (R.A.) \\ * Correspondence: m.giezen@uva.nl
}

Received: 28 July 2018; Accepted: 11 September 2018; Published: 19 September 2018

\begin{abstract}
In order to achieve the ambitious Sustainable Development Goal \#11 (Sustainable Cities and Communities), an integrative approach is necessary. Complex outcomes such as sustainable cities are the product of a range of policies and drivers that are sometimes at odds with each other. Yet, traditional policy assessments often focus on specific ambitions such as housing, green spaces, etc., and are blind to the consequences of policy interactions. This research proposes the use of remote sensing technologies to monitor and analyse the resultant effects of opposing urban policies. In particular, we will look at the conflicting policy goals in Amsterdam between the policy to densify, on the one hand, and, on the other hand, goals of protecting and improving urban green space. We conducted an analysis to detect changes in land-uses within the urban core of Amsterdam, using satellite images from 2003 and 2016. The results indeed show a decrease of green space and an increase in the built-up environment. In addition, we reveal strong fragmentation of green space, indicating that green space is increasingly available in smaller patches. These results illustrate that the urban green space policies of the municipality appear insufficient to mitigate the negative outcomes of the city's densification on urban green space. Additionally, we demonstrate how remote sensing can be a valuable instrument in investigating the net consequences of policies and urban developments that would be difficult to monitor through traditional policy assessments.
\end{abstract}

Keywords: urban green space; policy analysis; densification; resilience; Amsterdam; sustainability; SDGs

\section{Introduction}

The United Nations' Sustainable Development Goal \#11 (SDG11) presents the broad ambition of "inclusive, resilient and sustainable cities" [1]. However, this ambition is multifaceted, comprising incongruous policy goals and sectors. One crucial area of friction is apparent between the goal of compact city (CC) development (important for reduced transportation, resource, and land usage, etc.) and urban green space (UGS) goals (important in for example liveability, biodiversity, and climate regulation). Simply put, constrained development within limited space towards meeting densification goals puts increasing pressure on green space within urban areas. While traditional policy evaluations conventionally limit themselves to evaluating goals internal to each policy, we argue that it is essential to consider the net effect of multiple and conflicting policies. We further propose the application of remote sensing as a valuable tool in identifying the net land-use changes deriving from multiple urban policy and development drivers. Our empirical focus turns to the case of Amsterdam, evaluating longitudinal changes in land-use through remote sensing analyses in the context of potentially conflicting urban policies. 
Herein, we focus on the two goals of urban green space (UGS) and compact city (CC) policies. Green spaces are central to the development of sustainable cities, providing essential ecosystems that are vital for mitigating and adapting to environmental problems induced by urbanisation and climate change [2-5]. The biophysical characteristics of UGS have several direct and indirect positive effects on health, air quality, climate regulation, biodiversity, and hydrology $[2,4,6,7]$. Therefore, it is not surprising that UGS policies have been introduced by cities around the globe [2] and are promoted by concepts such as the Biophilic City [8].

An even more dominant concept in urban strategies for sustainable development is compact city development [9]. The compact city is characterised by highly densified urban development patterns, mixed land-use, accessibility of local services and jobs, and an efficient public transport that links dense urban areas [5,10,11]. It is often lauded for sustainability advantages across a variety of environmental, economic and even social dimensions, seen as a counterbalance to urban sprawl that has been associated with problems of car dependency, high land consumption, and resource-consuming life-styles [9,12-14].

Considering these oft-implemented sustainability policy goals together, a majority of existing relevant studies contend that densification processes and UGS development are frequently opposing forces [5]. In other words, increasing the amount of dwellings and inhabitants within the existing urban fabric is generally related to a decrease of UGS. Amsterdam provides a fascinating case where both of these policy goals have been explicitly adopted, with limited research into their joint outcome with regards to land-use changes.

We argue that remote sensing as a method is especially well-suited to detecting spatial-temporal changes at the urban scale. In our case, this enables the assessment of green space developments as the outcome of the interplay between land-use policies focussing on densification and green space. Through our Amsterdam study, we hope to contribute to the increasing effort to demonstrate the potential of remote sensing in urban planning practices [3,15-18].

We begin with a literature review outlining the concept of the compact city, the contribution of urban green space to sustainable cities, and the interaction between both. We then present our methodology. This is followed by the results, with our subsequent discussion reflecting on the usefulness of remote sensing in assessing the outcome of conflicting urban land-use policies.

\section{The Compact City, Urban Green Space, and Sustainable Urban Development}

As indicated, a highly popularised concept in both academic literature and policy is the idea of the "compact city" in achieving sustainable urban development [9]. It is claimed that the compact city counteracts the negative effects of urban sprawl by (1) reducing transport and vehicle emissions through a more efficient public transport system and an urban layout which encourages walking and cycling; (2) lowering energy usage given that higher-density layouts use less energy than low-density areas with a similar population; (3) protecting rural land beyond the urban edge through the intensification of the use of existing urban land $[9,12-14]$. The key focus of the compact city is to densify within urban areas in order to prevent urban sprawl [13]. Densification can be achieved by either the development of new buildings in areas within the city which were previously undeveloped (infill), previously having a different function (transformation), or through replacing low-rise buildings with higher-rise buildings [5]. While popularly adopted, the compact city model has also garnered criticism since the 1990s. It is associated with higher concentrations of fine dust [19], more stress, and the loss of affordable housing [20]. Furthermore, while it protects green areas outside of the urban edge, compact city growth has been argued to lead to a loss of green space within the urban fabric $[3,5,21]$. This crucial last potential outcome clearly conflicts with the range of benefits associated with UGS towards sustainable urban development.

Central to the benefits of UGS is its contribution to the mitigation of the effects of climate change and environmental degradation [2-5]. For instance, areas around green spaces are found to be on average $1-4{ }^{\circ} \mathrm{C}$ cooler than built-up space not within close proximity to green space $[22,23]$. Green space 
can also filter out harmful air pollutants and thereby reduce levels of particulate matter and $\mathrm{NO}_{2}$ [24]. In addition, green space can contribute to dampening sound pollution in urban environments, resulting in up to $12 \mathrm{~dB}$ reduction in localised sound volumes [25]. Urban green space is an important strategy in climate-proofing the city by absorbing rain and reducing the runoff stress on infrastructure such as sewage systems [26,27]. UGS also clearly increases neighbourhood satisfaction by providing spaces for social interaction, education, exercise, and recreation, and thus makes a valuable contribution to the liveability of a city $[27,28]$. Finally, UGS provides ecosystem services to the elderly and provides them with safe spaces for recreation that are within their often-limited mobility range [13].

The balance between planning a compact city while simultaneously creating an urban environment that is liveable, sustainable, and resilient is a difficult challenge posed to policy makers and planners. There is increasing evidence of a global loss of green space because of densification policies. Yet, as Artmann et al. [13] state, "we lack integrative guidelines on how to manage trade-offs between urban densification and the provision of green space." It is a paradox of the sustainable city that is imposed by the constraints of space. The usage of green roofs and green walls are specific approaches in dealing with this conundrum, but these solutions are limited in accounting for green space loss in terms of its capacity for water retention, heat mitigation, and various liveability benefits (e.g., public spaces of recreation and interaction).

These urban transformations are occurring in both the Global North and the Global South. However, they often take place at different scales and speeds. In rapidly expanding cities such as Hanoi in Vietnam [29], Kuala Lumpur in Malaysia [30], and Dhaka in Bangladesh [17], the decrease of UGS is caused primarily by the removal of street trees and parks for new commercial and housing developments. The problems are exacerbated by the lack of green space policies and planning oversight, leading to the prioritization of a neo-liberal growth machine that often places profit above sustainability and liveability. In cities in the Global North where the expansion is not as rapid, densification is mainly attributed to infill development [5]. Due to a lack of specific regulatory policies, developers are often not incentivised to preserve green space. There remains a lack of policies that take a long-term perspective on the relation between compact urban development and UGS into account [17,31-33]. However, the relevance of such a perspective is underscored in the academic literature. For instance, Jim and Chan [10] have shown through a review of published articles and government documents in Hong Kong from 1980 to 2015 that the neglect of strategic UGS planning has resulted in the elimination of the quantity and quality of UGS. Similarly, a study on the frequency and distribution of green infrastructure installations across 100 local government areas in Australia has shown "that councils that offered policy instruments and guidance tended to have more green wall and green roof projects than those which have no such policies in place" [34].

The paradox of developing towards a compact city model and the protection of UGS has been neglected in traditional policy evaluations, as they are generally focussed on single policy outcomes. Remote sensing offers the possibility of assessing the net outcome of a range of conflicting policies with land-use impacts. Nonetheless, there are only a few studies that link remote sensing land-use classification to urban policies. In a study of urban areas in the UK, Dallimar et al. [3] show that, following changed planning policies, 13 cities became denser while also seeing UGS decrease. Byomkesh et al. [17] further show the drastic reduction of UGS in Dhaka. After exploring the existing UGS management and policies by interviewing fifty key informants and analysing policy documents, the authors found that the decrease can be attributed to low political motivation and lack of spatial policy and management. Such studies illustrate the responsive nature of land-use composition to planning policies, or alternatively, the lack thereof.

We propose the need to expand this field of research by using remote sensing to show the friction between policy goals that paradoxically both aim for a more sustainable city. As mentioned above, there is a lack of integrative instruments addressing the trade-off between densification and urban green space. Where land-use outcomes are expected, we see remote sensing as a crucial instrument to achieve a more integrative assessment of this trade-off. 


\section{Materials and Methods}

\subsection{Study Area}

To evaluate the usefulness of remote sensing in assessing the shift in UGS, we focus on the city of Amsterdam. Amsterdam is the largest city of the Netherlands with 853,312 inhabitants over an area of $219.3 \mathrm{~km}^{2}$ [35]. The city has experienced strong growth in the last decade [36], with a projection to achieve 1 million inhabitants by 2030. Our research focuses on the area within the Amsterdam (highway) inner ring zone. This area represents the urban core of the city, characterised by the highest urban concentration and growth in the city and will especially experience increasing pressure on its green space [37]. Thus, the study area reflects best where UGS and densification policies are most likely to be incompatible. The area within the inner ring road has a population of approximately 500,000 and covers around $71.17 \mathrm{~km}^{2}$. Figure 1 presents the location of the study area within the context of the country and municipal boundaries of Amsterdam.
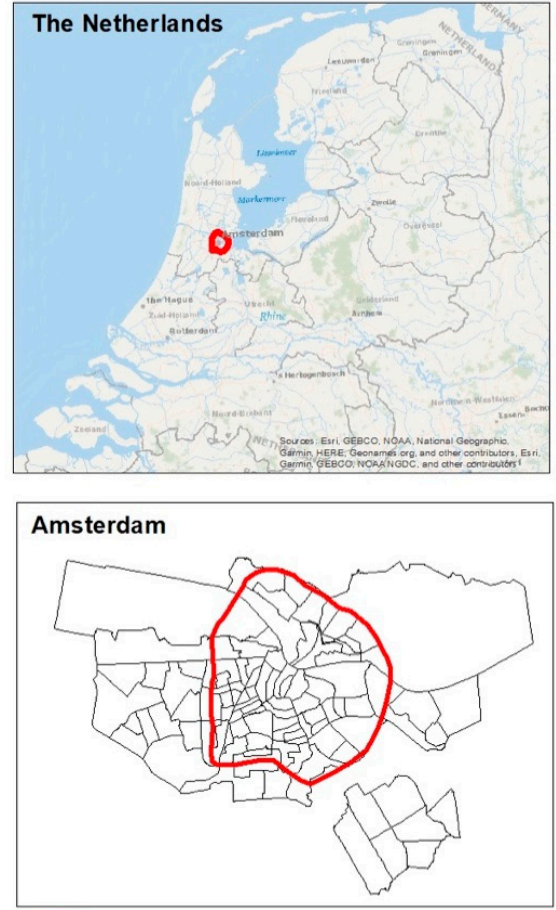

Amsterdam ring zone

Amsterdam neighbourhood borders

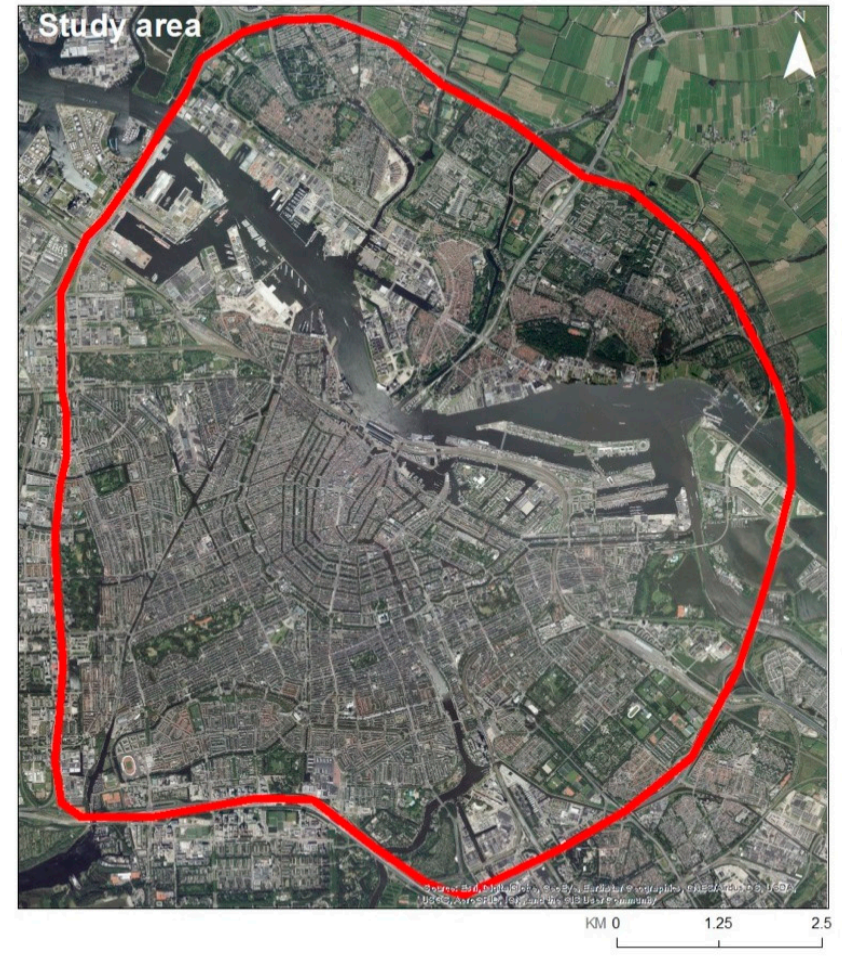

Figure 1. Study area: Amsterdam within the ring zone. Data sources: [38,39]. Design by authors.

\subsection{Data and Analysis}

\subsubsection{Data}

Green spaces in urban areas are typically fragmented, and thus imagery at medium resolutions cannot sufficiently detect land use dynamics since smaller patches of green space are often excluded. Therefore, high spatial resolution data is necessary to adequately quantify the spatial characteristics of urban green space [2,22,32]. High-resolution satellite images from Worldview 2 (0.46 m pixels) and Quickbird (0.64 m pixels) were used to carry out our land-use classification-retrieved from the Digital Globe satellite image repository. The selected images provide the highest possible resolution with $0 \%$ cloud coverage and were taken in the same season (months of September and July when vegetation is clearly visible. In addition, 2003 was the year after the first concretised UGS policy document [40]. It is the oldest high-resolution image matching the desired quality criteria and, as green space policies had barely been implemented in practice, it is useful in reflecting the situation previous to the city's green 
policy implementation. The most recent image matching our criteria is from 2016, and represents the situation following the most recent green space policy known as the "Green Agenda" [37]. Table 1 provides more detailed information on the satellite images.

Table 1. Satellite image and band information. Source: Digital Globe (2018). NIR: near-infrared.

\begin{tabular}{cccccc}
\hline Satellite & Bands Used & $\begin{array}{c}\text { Spectral Range } \\
\text { (newtonmeters) }\end{array}$ & $\begin{array}{c}\text { Spatial } \\
\text { Resolution (m) }\end{array}$ & $\begin{array}{c}\text { Satellite } \\
\text { Sensor (m) }\end{array}$ & $\begin{array}{c}\text { Acquisition Date and } \\
\text { Time (UTM + 1) }\end{array}$ \\
\hline \multirow{2}{*}{ Worldview 2 } & 7 (NIR 1) & $770-895$ & & & \\
& 5 (red) & $630-690$ & 1.84 & 0.46 & 25 September 2016 10:40 \\
& 3 (green) & $510-580$ & & & \\
Quickbird & 4 (NIR) & $760-900$ & & & \\
& 3 (red) & $630-690$ & 2.41 & & 16 July 2003 10:30 \\
& 2 (green) & $520-600$ & & & \\
\hline
\end{tabular}

\subsubsection{Land-Use Classification}

The images were rectified to the coordinate system of WGS84 zone $31 \mathrm{~N}$. The near-infrared (NIR), red, and green bands were used in the classification because they best highlight vegetation. The images were then classified into three land-use types: (a) urban (including built-up and barren land), (b) green space, and (c) water. Green space includes all vegetation areas visible from satellite imagery and therefore both public and private spaces were counted, since the wider definition of UGS is considered here where even green spaces that are not publicly accessible provide a multitude of environmental (and potentially aesthetic) benefits. In classifying the imagery, a supervised classification was performed using a minimum of 20 training sites per land-use class and per year. Subsequently, a maximum likelihood classification was carried out. On both the 2003 and 2016 land-use classified raster, steps were preformed to clean up small areas of misclassification. First, majority filter analysis was applied, which removed singular or very small clusters of pixels surrounded by a majority different land class. Secondly, a boundary clean was carried out which smoothed boundaries, prioritising larger areas over smaller ones. Lastly, a very limited number of manual adjustments were made in cleaning up some minor misclassifications. These manual corrections were only carried out where a misclassification error was clear across both years, so as to prevent any bias in corrections across the compared years.

Additionally, an accuracy assessment was employed to evaluate the agreement between the classification outcome and "reality". For each of the classified raster images, a sample of 180 random points were generated, equalized across the three classes. The ground-truthing assessment was carried out using the original image, as well as knowledge of the local area and, on rare occasions, cross-checking on Google Earth imagery when uncertainty arose (using images for the closest years from Google Earth). The overall accuracy and kappa coefficient of the derived classification output were respectively $96 \%$ and 0.93 for 2003 and $96 \%$ and 0.94 for 2016 (see Tables 2 and 3).

Table 2. Classification accuracy assessment (2003).

\begin{tabular}{cccccc}
\hline \multicolumn{5}{c}{ Ground Truth Reference Class } & \\
\hline & Green Space & Urban & Water & $\begin{array}{c}\text { Total } \\
\text { Sample }\end{array}$ & $\begin{array}{c}\text { User's } \\
\text { Accuracy }\end{array}$ \\
\hline Green space & 58 & 2 & 0 & 60 & $96.67 \%$ \\
Urban & 0 & 59 & 1 & 60 & $98.33 \%$ \\
Water & 0 & 5 & 55 & 60 & $91.67 \%$ \\
Producer's accuracy & $100.00 \%$ & $89.39 \%$ & $98.21 \%$ & & \\
\hline Overall classification accuracy & $\mathbf{9 5 . 5 6 \%}$ & & & & \\
Kappa coefficient & $\mathbf{0 . 9 3 3}$ & & & & \\
\hline
\end{tabular}


Table 3. Classification accuracy assessment (2016).

\begin{tabular}{cccccc}
\hline \multicolumn{5}{c}{ Ground Truth Reference Class } & \\
\hline & Green Space & Urban & Water & $\begin{array}{c}\text { Total } \\
\text { Sample }\end{array}$ & $\begin{array}{c}\text { User's } \\
\text { Accuracy }\end{array}$ \\
\hline Green space & 60 & 0 & 0 & 60 & $100.00 \%$ \\
Urban & 0 & 57 & 3 & 60 & $95.00 \%$ \\
Water & 0 & 4 & 56 & 60 & $93.33 \%$ \\
Producer's accuracy & $100.00 \%$ & $93.44 \%$ & $94.92 \%$ & & \\
\hline Overall classification accuracy & $\mathbf{9 6 . 1 1 \%}$ & & & & \\
Kappa coefficient & $\mathbf{0 . 9 4 2}$ & & & & \\
\hline
\end{tabular}

\subsubsection{Analysis}

Landscape metrics are often used to monitor land-use changes [33]. In our study, three key landscape metrics were measured to analyse the changing patterns of land-uses as used in similar research. For each land-use, we first measured the percentage shares and their changes over the period. Beyond percentages, we looked at more detailed metrics of changing spatial patterns. Both "patch density" and "shape index" were measured for the green space in Amsterdam in 2003 and 2016. Patch density expresses the number of disjoined areas per $\mathrm{km}^{2}$ and gives an indication of the overall level of fragmentation of the land-use [41]. The shape index is a measure of overall shape complexity. As opposed to a simple perimeter/area ratio, the shape index corrects for the size of patches and is a measure of the perimeter relative to the minimum possible perimeter for a given area. These metrics were calculated by first converting raster green areas to polygons, and small polygons were excluded using a simplify polygon function.

Subsequently, in order to calculate measures of distribution of close proximity to green space, $50 \mathrm{~m}$ buffers were calculated around green spaces larger than 300 and 500 square meters. Buffers of $50 \mathrm{~m}$ were chosen following the guidelines by Tudor and co-authors [42] for the optimal distance to green space. The green space thresholds of 300 and 500 square meters were chosen to exclude very small green spaces that are less likely to provide the expected benefits associated with UGS. These landscape metrics were selected because they give more detailed insights into the changing landscape patterns and are commonly employed in determining changing spatial patterns of land-use $[22,42,43]$.

\section{Results}

Figure 2 shows the changes of land-use for the urban core of Amsterdam (within the inner ring road). The three categories show water (blue), green space (green), and urban land including built-up and barren land (grey). Changes are highlighted in the 2016 map (bright green for new green space and red indicating lost green space). As expected, changes are relatively scattered, pointing to the fact that cities in the West primarily densify through infill [5]. Looking closely, there are clear developments in the North-Western harbour areas-on the map the area just north and west of the large body of water that dissects inner Amsterdam. On the south bank of this water body, known as the IJ, some more development is visible along the water way. These represent areas of recent transformation of industrial harbour land and their adjacent green or water spaces to new urban land development. In the very eastern edge of the map and between the water ways, there is a clear shift in development (representing the area known as Zeeburgereiland). 


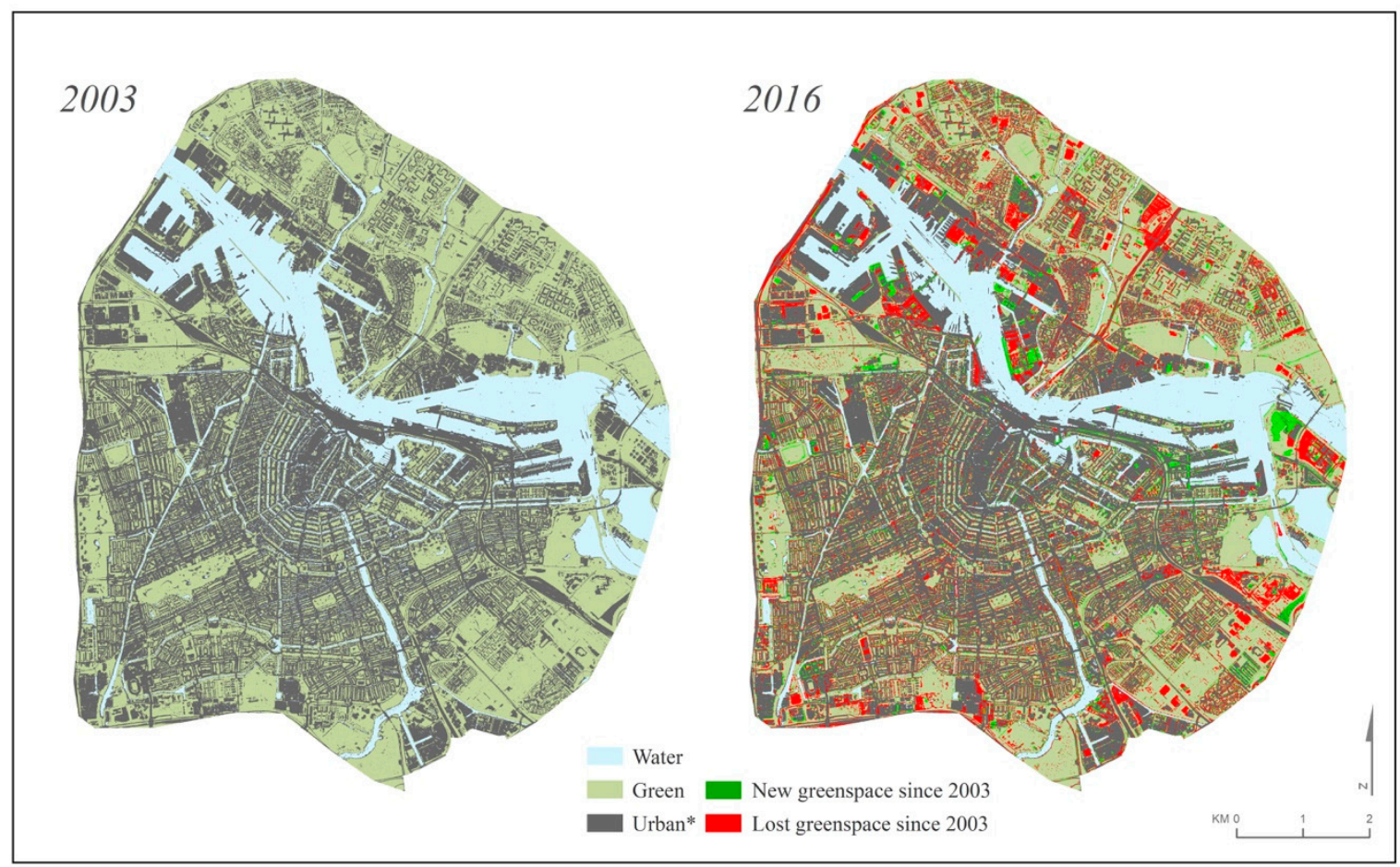

Figure 2. Land-use classification within Amsterdam core. Data Sources: Land-use classifications were made based on Worldview 2 satellite imagery for 2003 (resolution $0.46 \mathrm{~m}$ ) and Quickbird imagery for 2016 (resolution $0.64 \mathrm{~m}$ ). The data was provided by Digital Globe (2018) [44]. All calculations made by the authors. * urban land includes built-up as well as non-green barren land.

Table 4 reports the land-use metrics for 2003 and 2016 as well as the change over this period. The first crucial result is that the land-use share of green space clearly decreased in favour of the built-up urban environment. The total area of all green space that disappeared was 3.07 square kilometres-the equivalent of approximately 550-600 football fields. This means that a full $11 \%$ of the existing green space within the inner ring road of Amsterdam disappeared between 2003 and 2016. This is despite stated policy efforts in their Green Agenda programme to instead increase green space in the area [36]. While the rainproof strategy of Amsterdam aims to increase green space within the city as a preventative measure against flooding [36], in reality the efforts are not able to compensate for the densification of the city.

Looking at further metrics, we also see an increase in patch density, with an increase of about $20 \%$. This implies that green spaces became smaller on average in Amsterdam (i.e., more patches per square kilometre). Excluding the smallest patches (under 300 square meters), there was still a decrease, although much more minimal. In principal, small green patches are in line with the municipality's strategy of "post-stamp parks" that state a preference for smaller areas of green closer to people over larger areas of green space further away. However, the goal is in fact undermined by reduced total green space and distribution measures. Figure 3 and the distribution measures in table 4 reveal a decrease of the share of urban land within $50 \mathrm{~m}$ of green space. In other words, there is in fact a clear reduction of green space combined with a fragmentation of the existing green space. This has meant that even though there was an increase in the total number of green patches, the total urban area in proximity to green space still decreased. Finally, in addition to the fragmentation measure of patch density, the shape index further indicated an increasing complexity in the shape of green space areas. This may be the outcome of irregular encroachment upon green spaces, whereby increasingly complex shapes have potential implications on their use function. 
Table 4. Land-use statistics for the urban core of Amsterdam.

\begin{tabular}{|c|c|c|c|}
\hline & 2003 & 2016 & $\begin{array}{l}\text { Change } \\
2003-2016\end{array}$ \\
\hline \multicolumn{4}{|l|}{ Land use shares } \\
\hline Green space & $39.95 \%$ & $35.71 \%$ & -4.24 \\
\hline urban $^{\mathrm{a}}$ & $44.52 \%$ & $49.86 \%$ & 5.34 \\
\hline Water & $15.53 \%$ & $14.43 \%$ & -1.10 \\
\hline Total area of green space $\left(\mathrm{km}^{2}\right)$ & 28.42 & 25.35 & -3.07 \\
\hline \multicolumn{4}{|l|}{ Shape measures } \\
\hline Patch Density of green spaces (patches per $\mathrm{km}^{2}$ of green space) & 735.23 & 882.12 & 146.88 \\
\hline $\begin{array}{l}\text { Patch Density of green spaces (patchers per } \mathrm{km}^{2} \text { of green space) } \\
\text { excluding small patches under } 300 \mathrm{~m}^{2}\end{array}$ & 168.82 & 166.07 & -2.75 \\
\hline $\begin{array}{l}\text { Shape Index }{ }^{b} \text { of green space (perimeter/minimum possible perimeter } \\
\text { based on area) }\end{array}$ & 154 & 152 & -2.34 \\
\hline $\begin{array}{l}\text { Shape Index }{ }^{b} \text { of green space (perimeter/minimum possible perimeter } \\
\text { based on area) excluding small patches under } 300 \mathrm{~m}^{2}\end{array}$ & 129 & 116 & -12.79 \\
\hline \multicolumn{4}{|l|}{ Distribution measures } \\
\hline Percent of urban land within $50 \mathrm{~m}$ from green space of at least $300 \mathrm{~m}^{2}$ & $90.77 \%$ & $88.48 \%$ & -2.29 \\
\hline Percent of urban land within $50 \mathrm{~m}$ from green space of at least $500 \mathrm{~m}^{2}$ & $87.98 \%$ & $85.23 \%$ & -2.75 \\
\hline \multicolumn{4}{|c|}{$\begin{array}{l}\text { Data Sources: Land-use classsifications were made based on Worldview } 2 \text { satelite imagery for } 2003 \text { (resolution } \\
0.46 \mathrm{~m} \text { ) and Quickbird imagery for } 2016 \text { (resolution } 0.64 \mathrm{~m} \text { ). The data was provided by Digital Globe (2018) [44]. } \\
\text { All calculations made by the authors. Notes: }{ }^{\mathrm{a}} \text { aurban land includes built-up as well as non-green barren land. } \\
\text { b Shape Index is a measure of overall shape complexity. As opposed to a simple perimiter/area ratio, the shape } \\
\text { index corrects for the size of patches and is a measure of the perimeter relative to the minimum possible perimeter } \\
\text { given the area }\end{array}$} \\
\hline
\end{tabular}

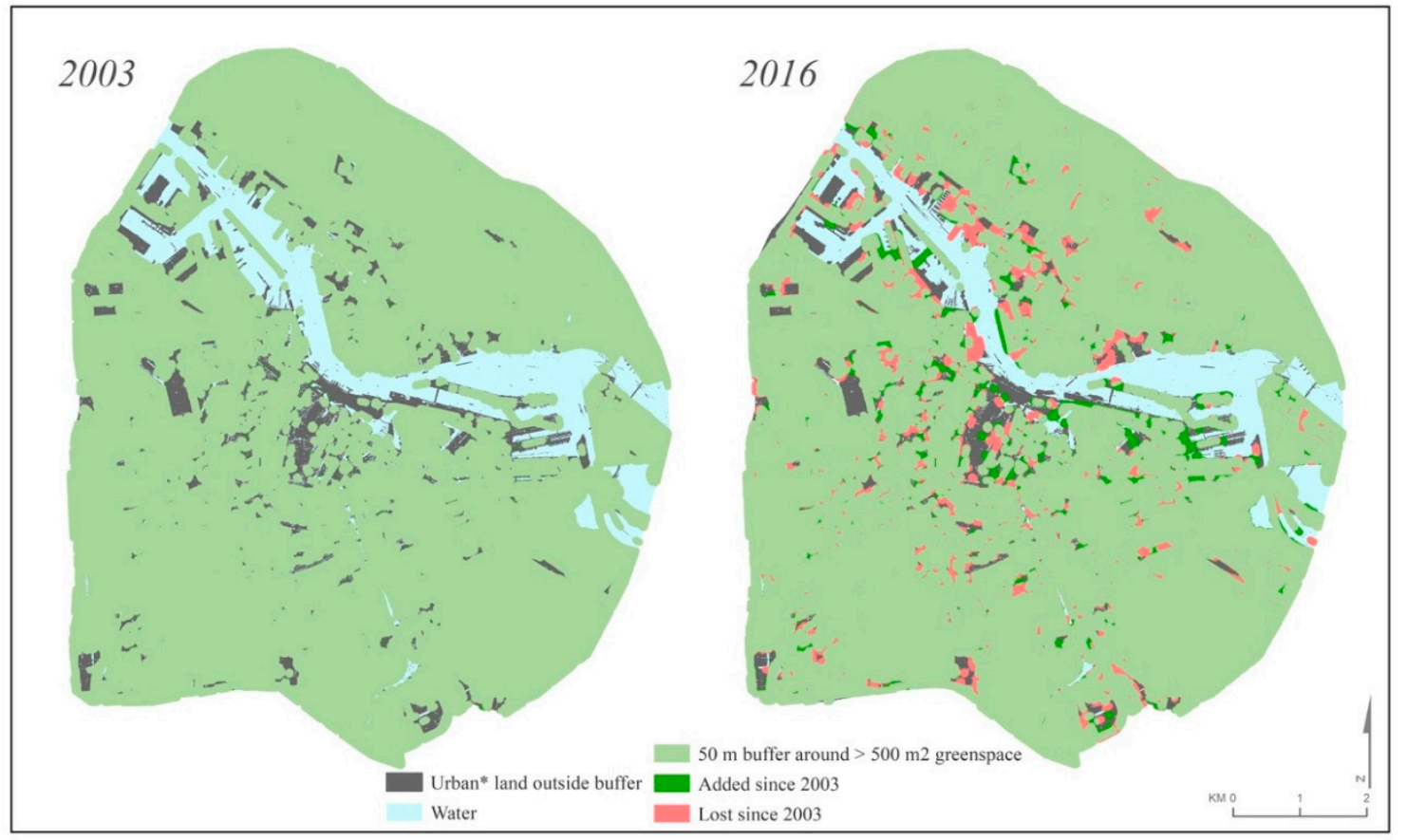

Figure 3. Distribution and proximity to green space within Amsterdam ring zone. Data Sources: Land-use classifications were made based on Worldview 2 satellite imagery for 2003 (resolution $0.46 \mathrm{~m}$ ) and Quickbird imagery for 2016 (resolution $0.64 \mathrm{~m}$ ). The data was provided by Digital Globe (2018) [44] All calculations made by the authors. * urban land includes built-up as well as non-green barren land.

It is interesting to compare these results to the ambitions of the Amsterdam municipality's Green Agenda [37] and its own monitoring report after two years [45]. Some of the key ambitions of the Green Agenda are:

- Improvement of the quality of urban parks (p. 12);

- More green space in the city for a pleasant living environment, cooling, and water storage (p. 17); 
- More and better green space in neighbourhoods (p. 23);

- Having increased proximity to green space through post-stamp parks, trees, or front gardens (p. 23).

If we then take a look at the subsequent monitoring report two years later [46], the municipality reports the following successes:

- An increase in green roofs of $40,000 \mathrm{~m}^{2}$;

- An increase of 16 post stamp parks;

- 21 school courtyards greened.

While these are indeed successes considering the limited amount of funds available for the green policies, the municipality had only to look from above, so to speak, to see that the green policy was in fact starkly inadequate in accomplishing their ambitions for more and better green space. The results of our remote sensing analysis clearly show that, even within the inner ring road, the loss of green space was 76 times greater over the previous decade or so than the subsequent minor increase through green roofs reported by the Green Agenda. It also shows that the accessibility of green space for the inhabitants within the urban core of the city also decreased substantially. Clearly, the UGS policy of the municipality of Amsterdam is insufficient to accomplish their stated ambitions when taking into consideration other simultaneous developments such as city densification. Interestingly, the municipal monitoring report does not show these clear contradictions, and only reports on a limited scope of successes of the policy. This ignores a crucial holistic assessment of the impact of net land-use changes.

Such discrepancies underscore the problem we introduced regarding traditional policy assessment and monitoring, as these do not adequately take full contextual developments into consideration. It is crucial to understand the dynamic multi-faceted nature of the city, where developments are often polycentrically governed by a wide range of actors and departments. Multiple agendas do not necessarily work in unison, and as we have pointed out, may in some cases be in direct conflict. It is in this context of frequently partial and disjointed policy monitoring that tools such as remote sensing provide a vital method to look at dynamics such as net land-use changes following multiple and potentially contradicting policies. It is not implied that traditional policy monitoring has no place, but tools such as remote sensing analysis provide valuable supplementary information, especially in cases where spatial dynamics play out at the city-scale and a holistic assessment is fundamental to understanding contradictory policy goals.

\section{Discussion}

The results of the analysis show that there is an inherent difficulty in developing a city that is both green and compact. Densification of the inner city can be achieved by either filling in open spaces or increasing the height of the buildings. The latter is of course difficult in a historical city such as Amsterdam. This is also a limitation of the research, as there are more possibilities to move to high-rise buildings in less-historical cities. However, as Haaland and Van den Bosch [5] argue, there is evidence across the globe in many different contexts that densification leads to a reduction of UGS. As can be seen from the Green Agenda by the municipality of Amsterdam, a work-around is to focus on the quality of the green space. However, this is extremely difficult to measure and one can also wonder if improvements of quality can compensate the large loss of green space within the city. Many of the benefits identified with UGSs, such as on health, air quality, climate regulation, biodiversity, and hydrology $[2,4,6,7]$, require that there is a sufficient amount of space available. For instance, the capacity to accommodate rainfall is primarily influenced by the total surface, as an increase in surface sealing leads to increased water runoff [46]. In addition, the accessibility to urban green spaces, especially for elderly individuals [13], is important. It is clear that the Green Agenda is unable to compensate for the amount of lost green space. The decrease of urban green space by $11 \%$ in the inner city was accompanied over the same period by a large increase in the population of Amsterdam: from 743,104 to 852,011 -an increase of $7 \%$. At the same time, there was an increase of $7 \%$ in the total number of dwellings. This population growth and new dwelling construction seems to be a direct cause of 
green space loss, as a large proportion of the areas where there was a loss of green were designated as development areas. This growth, combined with a policy of densification through preservation and infilling, is likely to have caused the large decrease in urban green space. A further important contributor seems to be the shift to artificial grass for sports activities. While artificial grass looks green and is counted in municipal statistics as 'recreational green,' it would not be calculated as green by an NVDI analysis based on vegetation cover. Remote sensing thus provides additional insights to standard statistics, as it includes all actual changes in green space. Shifts to artificial grass, paving over private gardens, and other non-statistical land use changes are captured in satellite imagery, but often neglected in official statistics. This capacity of remote sensing is even more important in contexts where up-to-date spatial data is simply not available.

The results also show an increase in fragmentation. On the one hand this is likely attributable to the densification, as larger areas get (partially) filled in or divided up. On the other hand, it also directly reflects the focus of the Green Agenda on small green spaces and a purported commitment to quality over quantity. However, when considering issues such as urban biodiversity, the fragmentation of green space is related to an important loss of habitat for species $[47,48]$, and therefore quality cannot be decoupled from absolute area measures and connections between different green spaces. The fragmentation also explains the minor reduction of access to green space shown in Table 4 in comparison to the total amount of green space lost. Of course, a limitation of this research is that it cannot show whether or not the green space is truly accessible for all within its radius or if it is private space that is not open to the public.

The densification strategy of the compact city has led to a strong decrease in the total amount of green space and a fragmentation of green areas within the inner ring road of Amsterdam. As these results attest, the Green Agenda of the municipality is insufficient in mitigating the UGS consequences of compact city development. Nonetheless, the official evaluation of the Green Agenda has still presented it as a success within the scope of a selective set of goals and ambitions. The usage of remote sensing is therefore crucial, as it presents a "reality check" by confronting holistic measures of net land use change. Remote sensing can thus provide a crucial additional perspective to policy evaluation and represents an invaluable contribution to the toolbox of planners and government officials in assessing developments within their jurisdiction.

While the urban core of the city represents the area where contradicting goals of densification and green space may most intensely come to the fore, this focus of the study area also impacts the generalizability of the research in several ways. Firstly, the specific historical character of the inner area of Amsterdam forces an infill strategy. This implies that options for high-rise development are more restricted than in cities without a historical core. Secondly, large-scale developments often happen at the outer fringes of cities, where green field development is still possible. The total decrease of green space within the full city region is therefore difficult to extrapolate from our urban core focus - and admittedly beyond the intended focus of the research. This makes it more difficult to compare to city-scale research for other cities in Western Europe. Nonetheless, the case study presented underscores the valuable potential of remote sensing in assessing the net result of the conflicting policy goals of densification and greenification, particularly within the context of historical urban cores where such paradoxes may be more intractable. The research clearly illustrates that the capacity of Amsterdam's green space policy is insufficient in counterbalance the associated development pressures of its compact city strategy.

\section{Conclusions}

Green spaces are central to the development of sustainable cities, providing essential ecosystems that are vital for mitigating and adapting to environmental problems induced by urbanisation and climate change [2-5]. As such, policies promoting urban green space (UGS) are an important piece of the solution for urbanized regions in achieving Sustainability Development Goals. At the same time, the compact city is promoted as a sustainable development concept that is also promoted as 
crucial to reaching SDGs. These two strategies of increasing UGS and increasing densification are often at odds. In many cases, the pressure for densification is greater than the ability of UGS policy to compensate for the land-use change. However, traditional policy monitoring and evaluation strategies have focused largely on the results internal to specific policies while failing to clearly evaluate whether both UGS and compact city policies are simultaneously successful. Remote sensing offers the potential to incorporate the effects of a wide range of developments and policies by focusing on detailed net land-use changes at neighbourhood, city area, or urban region scales.

In our empirical case of Amsterdam, we show how the use of remote sensing can be a valuable tool in evaluating land-use policies. Here, we demonstrate how even municipal UGS policies considered to be a success in terms of limited internal goals are completely inadequate in mitigating the loss of green space in the face of urban densification. The $40,000 \mathrm{~m}^{2}$ of green roofs is a drop in the bucket towards compensating the 3 million $\mathrm{m}^{2}$ of green space lost over the previous decade or so. If cities are serious in their ambitions to make use of green space to help adapt to climate change, improve air quality, or contribute to liveability, a coordinated shift in policies will be necessary. For this, assessment tools are essential that can take net change within the city into consideration. Remote sensing is a crucial supplement to traditional policy evaluation and monitoring tools given its ability to evaluate overall land-use change irrespective of policy ambitions. It provides the essential bird's-eye (or satellite's-eye) view allowing governments to assess and plan a holistic integration of development and policy goals. It can further be key in identifying contradictory dynamics and in finding ways to mitigate and overcome them. From the sky, it can become clear that a policy boasting internal successes might, in fact, be ineffective considering other development and policy ambitions. In other words, for an effective on-the-ground implementation of the SDGs, a bigger picture perspective of on-the-ground developments is vital. High-quality remote sensing is, par excellence, the bigger picture.

Author Contributions: For research articles with several authors, a short paragraph specifying their individual contributions must be provided. The following statements should be used "Conceptualization, M.G. and S.B.; Methodology, S.B and R.A.; Software, S.B and R.A.; Validation, M.G., S.B. and R.A.; Formal Analysis, M.G., S.B.; Investigation, S.B.; Resources, S.B.; Data Curation, S.B.; Writing-Original Draft Preparation, M.G.; Writing-Review \& Editing, M.G. and R.A.; Visualization, S.B. and R.A.; Supervision, M.G.; Project Administration, M.G.; Funding Acquisition, N.A.", please turn to the CRediT taxonomy for the term explanation. Authorship must be limited to those who have contributed substantially to the work reported.

Funding: This research received no external funding

Acknowledgments: We would like to thank the Urban Green City Watch team and DigitalGlobe for providing the satellite imagery. In addition, our gratitude goes to the help provided by Karin Pfeffer and Robbin Jan van Duijne in the development of the project.

Conflicts of Interest: The authors declare no conflict of interest.

\section{References}

1. United Nations. Transforming Our World: The 2030 Agenda for Sustainable Development; United Nations: New York, NY, USA, 2015.

2. Zhou, W.; Wang, J.; Qian, Y.; Pickett, S.T.; Li, W.; Han, L. The rapid but "invisible" changes in urban greenspace: A comparative study of nine Chinese cities. Sci. Total Environ. 2018, 627, 1572-1584. [CrossRef]

3. Dallimar, M.; Tang, Z.; Bibby, P.R.; Brindley, P.; Gaston, K.J.; Davies, Z.G. Temporal changes in greenspace in a highly urbanized region. Biol. Lett. 2011. [CrossRef] [PubMed]

4. Kabisch, N. Ecosystem service implementation and governance challenges in urban green space planning-The case of Berlin, Germany. Land Use Policy 2015, 42, 557-567. [CrossRef]

5. Haaland, C.; van den Bosch, C.K. Challenges and strategies for urban green-space planning in cities undergoing densification: A review. Urban For. Urban Green. 2015, 14, 760-771. [CrossRef]

6. ten Brink, P.; Mutafoglu, K.; Schweitzer, J.-P.; Kettunen, M.; Twigger-Ross, C.; Baker, J.; Kuipers, Y.; Emonts, M.; Tyrväinen, L.; Hujala, T.; et al. The Health and Social Benefits of Nature and Biodiversity Protection; Institute for European Environmental Policy: London, UK; Brussels, Belgium, 2016. 
7. Roy, S.; Byrne, J.; Pickering, C. A systematic quantitative review of urban tree benefits, costs, and assessment methods across cities in different climatic zones. Urban For. Urban Green. 2012, 11, 351-363. [CrossRef]

8. Beatley, T.; Newman, P. Biophilic Cities Are Sustainable, Resilient Cities. Sustainability 2013, 5, 3328-3345. [CrossRef]

9. Burton, E.; Jenks, M.; Williams, K. (Eds.) The Compact City: A Sustainable Urban Form? Routledge: Abingdon, UK, 2003.

10. Jim, C.Y.; Chan, M.W. Urban greenspace delivery in Hong Kong: Spatial-institutional limitations and solutions. Urban For. Urban Green. 2016, 18, 65-85. [CrossRef]

11. Westerink, J.; Haase, D.; Bauer, A.; Ravetz, J.; Jarrige, F.; Aalbers, C.B. Dealing with sustainability trade-offs of the compact city in peri-urban planning across European city regions. Eur. Plan. Stud. 2013, 21, 473-497. [CrossRef]

12. Jabareen, Y. Planning the resilient city: Concepts and strategies for coping with climate change and environmental risk. Cities 2013, 31, 220-229. [CrossRef]

13. Artmann, M.; Kohler, M.; Meinel, G.; Gan, J.; Ioja, I.C. How smart growth and green infrastructure can mutually support each other-A conceptual framework for compact and green cities. Ecol. Indic. 2017. [CrossRef]

14. Dantzig, G.B.; Saaty, T.L. Compact City: A Plan for a Liveable Urban Environment; WH Freeman: New York, NY, USA, 1973.

15. Baud, I.; Kuffer, M.; Pfeffer, K.; Sliuzas, R.; Karuppannan, S. Understanding heterogeneity in metropolitan India: The added value of remote sensing data for analyzing sub-standard residential areas. Int. J. Appl. Earth Obs. Geoinf. 2010, 12, 359-374. [CrossRef]

16. Patino, J.E.; Duque, J.C. A review of regional science applications of satellite remote sensing in urban settings. Comput. Environ. Urban Syst. 2013, 37, 1-17. [CrossRef]

17. Byomkesh, T.; Nakagoshi, N.; Dewan, A.M. Urbanization and green space dynamics in Greater Dhaka, Bangladesh. Landsc. Ecol. Eng. 2012, 8, 45-58. [CrossRef]

18. Mahmoodzadeh, H. Digital change detection using remotely sensed data for monitoring green space destruction in Tabriz. Int. J. Environ. Res. 2007, 1, 35-41.

19. Schweitzer, L.; Zhou, J. Neighborhood air quality, respiratory health, and vulnerable populations in compact and sprawled regions. J. Am. Plan. Assoc. 2010, 76, 363-371. [CrossRef]

20. Burton, E. The compact city and social justice. In Proceedings of the Housing Studies Association Spring Conference: Housing, Environment and Sustainability, York, UK, 18-19 April 2001.

21. Xu, C.; Haase, D.; Pauleit, S. The impact of different urban dynamics on green space availability: A multiple scenario modeling approach for the region of Munich, Germany. Ecol. Indic. 2018, 93, 1-12. [CrossRef]

22. Qian, Y.; Zhou, W.; Yu, W.; Pickett, S.T. Quantifying spatiotemporal pattern of urban greenspace: New insights from high resolution data. Landsc. Ecol. 2015, 30, 1165-1173. [CrossRef]

23. Oliveira, R.P.; Perego, P.; de Oliveira, M.N.; Converti, A. Effect of inulin as prebiotic and synbiotic interactions between probiotics to improve fermented milk firmness. J. Food Eng. 2011, 107, 36-40. [CrossRef]

24. Pugh, T.A.; MacKenzie, A.R.; Whyatt, J.D.; Hewitt, C.N. Effectiveness of green infrastructure for improvement of air quality in urban street canyons. Environ. Sci. Technol. 2012, 46, 7692-7699. [CrossRef] [PubMed]

25. Van Renterghem, T.; Forssén, J.; Attenborough, K.; Jean, P.; Defrance, J.; Hornikx, M.; Kang, J. Using natural means to reduce surface transport noise during propagation outdoors. Appl. Acoust. 2015, 92, 86-101. [CrossRef]

26. Alekseeva, I.; Menshikh, D.; Kudryavtseva, O.V. Greening as an element of sustainable urban development: Valuation of economic feasibility, policyassessment and practical examples. Вестник Российского Университета Аружбы народов. Серия: Агрономия и Животноводство 2016, 4, 51-62. [CrossRef]

27. Zhang, Y.; Van den Berg, A.E.; Van Dijk, T.; Weitkamp, G. Quality over quantity: Contribution of urban green space to neighborhood satisfaction. Int. J. Environ. Res. Public Health 2017, 14, 535. [CrossRef] [PubMed]

28. Ioja, C.L.; Nita, M.R.; Vanau, G.O.; Onose, D.A.; Gavrilidis, A.A. Using multi-criteria analysis for the identification of spatial land-use conflicts in the Bucharest Metropolitan Area. Ecol. Indic. 2014, 42, 112-121. [CrossRef]

29. Uy, P.D.; Nakagoshi, N. Analyzing urban green space pattern and eco-network in Hanoi, Vietnam. Landsc. Ecol. Eng. 2007, 3, 143-157. [CrossRef] 
30. Nor Akmar, A.A.; Konijnendijk, C.C.; Sreetheran, M.; Nilsson, K. Greenspace planning and management in Klang valley, Peninsular Malaysia. Urban For. 2011, 37, 99-107.

31. Brunner, J.; Cozens, P. 'Where have all the trees gone?' Urban consolidation and the demise of urban vegetation: A case study from Western Australia. Plan. Pract. Res. 2013, 28, 231-255. [CrossRef]

32. Zhou, X.; Wang, Y.C. Spatial-temporal dynamics of urban green space in response to rapid urbanization and greening policies. Landsc. Urban Plan. 2011, 100, 268-277. [CrossRef]

33. Tian, Y.; Jim, C.Y.; Tao, Y. Challenges and strategies for greening the compact city of Hong Kong. J. Urban Plan. Dev. 2012, 138, 101-109. [CrossRef]

34. Irga, P.J.; Braun, J.T.; Douglas, A.N.J.; Pettit, T.; Fujiwara, S.; Burchett, M.D.; Torpy, F.R. The distribution of green walls and green roofs throughout Australia: Do policy instruments influence the frequency of projects? Urban For. Urban Green. 2017, 24, 164-174. [CrossRef]

35. CBS. Kerncijfers wijken en buurten 2018. Available online: http://statline.cbs.nl/Statweb/ (accessed on 2 July 2018).

36. CBS/PBL. Regionale Prognose 2016-2040; Centraal Bureau voor de Statistiek: Den Haag, The Netherlands, 2016.

37. Gemeente Amsterdam. Agenda Groen; Gemeente Amsterdam: Amsterdam, The Netherlands, 2015.

38. Gemeente Amsterdam. Interactieve kaarten. Available online: https://maps.amsterdam.nl/ (accessed on 20 May 2018).

39. Openstreetmap. Openstreetmap. Available online: https://www.openstreetmap.org/\#map=14/49.1388/ -102.9961 (accessed on 20 May 2018).

40. Gemeente Amsterdam. De Hoofdgroenstructuur Geordend; Gemeente Amsterdam: Amsterdam, The Netherlands, 2002.

41. McGarigal, K. Fragstats Help; University of Massachusetts: Amherst, MA, USA, 2015.

42. Tudor, M.; Radoslav, R.; Spiridon, L.C.; Păcurar, L. Assessing pedestrian accessibility to green space using GIS. Transylv. Rev. Adm. Sci. 2014, 10, 116-139.

43. Maimaitijiang, M.; Ghulam, A.; Sandoval, J.O.; Maimaitiyiming, M. Drivers of land cover and land use changes in St. Louis metropolitan area over the past 40 years characterized by remote sensing and census population data. Int. J. Appl. Earth Obs. Geoinf. 2015, 35, 161-174. [CrossRef]

44. Digital Globe. Digital globe. Available online: https:/ / discover.digitalglobe.com/ (accessed on 20 May 2018).

45. Gemeente Amsterdam. Monitor Agenda Groen December 2017; Gemeente Amsterdam: Amsterdam, The Netherlands, 2017.

46. Gill, S.E.; Handley, J.F.; Ennos, A.R.; Pauleit, S. Adapting Cities for Climate Change: The Role of the Green Infrastructure. Built Environ. 2007, 33, 115-133. [CrossRef]

47. Jim, C.Y. Green-space preservation and allocation for sustainable greening of compact cities. Cities 2004, 21, 311-320. [CrossRef]

48. Kong, F.; Yin, H.; Nakagoshi, N.; Zong, Y. Urban green space network development for biodiversity conservation: Identification based on graph theory and gravity modeling. Landsc. Urban Plan. 2010, 95, 16-27. [CrossRef]

(C) 2018 by the authors. Licensee MDPI, Basel, Switzerland. This article is an open access article distributed under the terms and conditions of the Creative Commons Attribution (CC BY) license (http://creativecommons.org/licenses/by/4.0/). 